\title{
Avaliação da moagem e granulometria do milho e consumo de energia no processamento em moinhos de martelos
}

\author{
Evaluation of corn grinding and particle size and energy consumption in \\ the processing on hammermills
}

\author{
Paulo Cesar Pozza1 ${ }^{1}$ Magali Soares dos Santos Pozza ${ }^{2}$ Silvano Richart ${ }^{3}$ \\ Fernando Gavlik de Oliveira $^{3}$ Emerson Silveira Gasparotto ${ }^{3}$ Fabiano Schlickmann ${ }^{3}$
}

\begin{abstract}
- NOTA
RESUMO

Foi realizado um trabalho com o objetivo de avaliar a granulometria do milho, a taxa de moagem, o consumo de energia elétrica de diferentes moinhos de martelos e determinar as características dos moinhos que influenciam o diâmetro geométrico médio das partículas. Para determinar os preditores da granulometria, as características dos moinhos foram consideradas as variáveis independentes utilizando o procedimento estatístico "Backward" para obtenção das equações. A equação para estimar o diâmetro geométrico médio das partículas que proporcionou um maior $R^{2}(0,85)$ foi a seguinte: $330,59+494,284 T X-11,844 P M+113,746 D P$ - 0,186ATP. A variação da taxa de moagem e consumo de energia elétrica, de moinhos de martelos, pode ser devido às

geometric diameter of the particles. To determine the corn particle size predictors and the hammermills characteristics, the independent parameters were considered using the "Backward" statistical process to obtain the equations. The equation to estimate the average geometric diameter that showed the higher $R^{2}(0.85)$ was: $330.59+494.284 T X-$ $11.844 P M+113.746 D P-0.186 A T P$. The grinding rate variation and the electric power consumption, of the hammermills, can be due to the differences among the characteristics of the mills, the wasting due to the use and of the potency of the motors of the mills. It was ended that the grinding rate and the diameter of the hole sieves' showed a positive relationship with the average geometric diameter, and the engine power and the total sives' area showed a negative relationship.
\end{abstract} diferenças entre as características dos moinhos, do desgaste devido ao uso e da potência dos motores que equipam os moinhos. Concluiu-se que a taxa de moagem e o diâmetro dos furos das peneiras apresentaram uma correlação positiva com o diâmetro geométrico médio, e a potência do motor e a área total da peneira, uma correlação negativa.

Palavras-chave: características dos moinhos, diâmetro geométrico médio, equações de estimativa.

\section{ABSTRACT}

A study was carried out to evaluate the particle size of the corn, the performance and electric power consumption of hammermills and to determine the hammermills characteristics that influence the average
Key words: geometric diameter, equations, hammermills.

Dentre os ingredientes utilizados nas formulações de ração, o milho tem participado normalmente com 70 a $80 \%$ da composição total da ração. Acredita-se que uma das formas possíveis de melhor viabilizar o setor possa ser por meio da geração de informações mais precisas sobre o grau de moagem do milho, que permitiria a escolha da granulometria que proporcionasse o melhor aproveitamento dos nutrientes (ZANOTTO et al., 1995).

\footnotetext{
${ }^{1}$ Zootecnista, Doutor, Professor Adjunto, Universidade Estadual do Oeste do Paraná (UNIOESTE), 85960-000, Marechal Cândido Rondon, PR. E-mail: pcpozza@hotmail.com. Autor para correspondência.

${ }^{2}$ Zootecnista, Mestre, Professor Assistente, UNIOESTE.

${ }^{3}$ Acadêmico do curso de Zootecnia, UNIOESTE.
} 
O grau de moagem é caracterizado de acordo com o tamanho das partículas e, em geral, se utiliza uma variável que é o diâmetro geométrico médio (DGM), o qual se correlaciona de forma positiva com o tamanho das partículas. Segundo BIAGI (1998), a redução de tamanho dos grãos se inicia com a retirada das camadas externas e esta redução modifica as características físicas e pode melhorar os processos de mistura, peletização, manuseio e transporte.

Os moinhos de martelos têm sido preferencialmente utilizados, uma vez que possibilita o processamento de maior variedade de ingredientes (fibrosos) e permite a produção de moagens mais finas (<600mm) em relação ao moinho de rolos (MARTIN, 1988).

No entanto, as variações existentes entre as características dos moinhos podem influenciar a granulometria do milho processado em moinhos de martelos, devendo ser considerados o diâmetro dos furos da peneira, a área de abertura da peneira, a potência do motor, o número de martelos, distância entre os martelos e a peneira, a vazão de moagem, o teor de umidade do grão e o desgaste do moinho (MARTIN, 1988).

Dessa forma, foi desenvolvido um trabalho com o objetivo de avaliar a granulometria do milho, o desempenho e consumo de energia elétrica de diferentes moinhos de martelos e determinar as características dos moinhos que influenciam o diâmetro geométrico médio das partículas.

O trabalho foi realizado em dez unidades produtoras de suínos e, na determinação da granulometria, desempenho e consumo de energia elétrica dos moinhos de martelos o milho utilizado foi de uma única procedência. Foi determinada a área total das peneiras (ATP), o diâmetro dos furos das peneiras (DP), a rotação do eixo do moinho antes da moagem (REMA) e durante a moagem (REMD) e o número de martelos (NM) de cada moinho avaliado. Foi atribuído um escore de desgaste dos martelos em que o escore zero ( 0 ) foi atribuído a um jogo de martelos novos, sem desgaste; escore 1: pequeno desgaste, caracterizado pela não existência de ângulos nos martelos; escore 2: desgaste moderado, atribuído a martelos com aproximadamente 2,0mm de desgaste em relação ao ângulo original; escore 3: caracterizado por desgaste maior que $2,0 \mathrm{~mm}$ em relação ao ângulo original.

Para avaliação do desempenho dos moinhos, foi utilizada a taxa de moagem (TX), obtida através da relação entre o tempo necessário para a moagem (TM) da quantidade (kg) de milho. De posse da potência do motor (PM), voltagem e perda de carga dos motores que equipavam os moinhos, foi calculado o consumo de energia elétrica na moagem (CEM - kWh $\left.\mathrm{t}^{-1}\right)$. Após realizada a moagem, as amostras foram submetidas a determinação do diâmetro geométrico médio (DGM) das partículas (HANDERSON \& PERRY, 1955).

As estimativas do DGM, em função das características dos moinhos, foram obtidas por meio de regressão linear simples e múltipla através da técnica de eliminação indireta (Backward) utilizando o Sistema de Análises Estatísticas e Genéticas - SAEG (UFV, 1999), considerando o diâmetro geométrico médio das partículas a variável dependente, e como variáveis independentes foram utilizados o diâmetro dos furos da peneira, a área total da peneira, a taxa de moagem e a potência do motor.

Observou-se uma alta variabilidade entre os valores de DGM obtidos para os diferentes moinhos avaliados, apresentando uma variação de 464 a 912mm (Tabela 1). Os diâmetros dos furos das peneiras apresentaram uma variação de 1,44 a 3,28mm, mostrando-se inferiores aos valores observados por OLIVEIRA et al. (1991), em um levantamento realizado em propriedades que produziam suas próprias rações, cujo diâmetro dos furos das peneiras variaram de 2,00 a 6,00mm. O número de martelos, dos moinhos avaliados, variou de 15 a 48 mostrando-se superiores aos observados pelos autores supracitados que foi de 10 a 28.

A área das peneiras e o escore de desgaste dos martelos (Tabela 1) tiveram uma grande variação entre os diferentes moinhos avaliados, apresentando intervalos de 618,45 a $2401,20 \mathrm{~cm}^{2}$ e 01 a 03 , respectivamente. Além disso, observa-se uma grande variação entre a rotação do eixo do moinho antes da moagem (3540 a 5334rpm) e durante a moagem (3540 a 5214rpm), entretanto, constatou-se, com exceção do moinho 10, que os moinhos equipados com motores com uma potência acima de $20 \mathrm{cv}$ não apresentaram uma redução na rotação do eixo do moinho durante a moagem em relação ao moinho vazio.

O consumo de energia elétrica na moagem (Tabela 1) variou de 6,13 a 20,03kWh t-1, que foi semelhante ao obtido por HEALEY et al. (1994) que foi de 5,3 a 24,5kWh t-1. Por outro lado, a taxa de moagem, variou de 0,2 a $2,1 \mathrm{t} \mathrm{h}^{-1}$, apresentando uma maior variação em relação ao obtido por HEALEY et al. (1994), que foi de 0,63 a $1,76 \mathrm{t} \mathrm{h}^{-1}$ para uma variação do diâmetro geométrico médio de 300 a 900 mm. A baixa taxa de moagem do moinho 6 pode ser reflexo da combinação entre a pequena área da peneira $\left(704,60 \mathrm{~cm}^{2}\right)$ e menor número de martelos (16), o que conseqüentemente proporcionou o maior consumo de 
Tabela 1 - Diâmetro geométrico médio (DGM), diâmetro dos furos das peneiras (DP), área total das peneiras (ATP), rotação do eixo do moinho antes da moagem (REMA) e durante a moagem (REMD), escore de desgaste dos martelos (EDM), número de martelos (NM), tempo de moagem (TM), taxa de moagem (TX), potência do motor (PM) e consumo de energia na moagem (CEM) em moinhos de martelos.

\begin{tabular}{|c|c|c|c|c|c|c|c|c|c|c|c|}
\hline Moinho & $\mathrm{DGM}(\mu \mathrm{m})$ & $\mathrm{DP}(\mathrm{mm})$ & $\operatorname{ATP}\left(\mathrm{cm}^{2}\right)$ & REMA(rpm) & REMD(rpm) & EDM & $\mathrm{NM}$ & $\mathrm{TM}\left(\mathrm{s}^{\prime}\right.$ & $\mathrm{TX}(\mathrm{t} / \mathrm{h})$ & $\mathrm{PM}(\mathrm{cv})$ & CEM $(\mathrm{KWh} / \mathrm{t})$ \\
\hline 1 & 464 & 1,44 & 1620,00 & 3540 & 3540 & 01 & 15 & 29 & 1,2 & 20,0 & 11,85 \\
\hline 2 & 794 & 2,97 & 782,00 & 4596 & 4344 & 01 & 16 & 47 & 0,8 & 10,0 & 9,60 \\
\hline 3 & 670 & 1,44 & 975,20 & 4860 & 4794 & 01 & 20 & 60 & 0,6 & 5,0 & 6,13 \\
\hline 4 & 912 & 2,89 & 1080,00 & 4134 & 3852 & 03 & 30 & 30 & 1,2 & 10,0 & 6,13 \\
\hline 5 & 587 & 2,77 & 1055,00 & 4266 & 3864 & 00 & 28 & 84 & 0,4 & 7,5 & 12,87 \\
\hline 6 & 492 & 2,83 & 704,60 & 5334 & 5214 & 01 & 16 & 196 & 0,2 & 5,0 & 20,03 \\
\hline 7 & 845 & 3,28 & 618,45 & 4320 & 4224 & 01 & 24 & 64 & 0,6 & 5,0 & 6,54 \\
\hline 8 & 718 & 3,03 & 2401,20 & 3600 & 3600 & 02 & 48 & 17 & 2,1 & 50,0 & 17,37 \\
\hline 9 & 706 & 2,99 & 2130,00 & 4062 & 4062 & 02 & 36 & 23 & 1,6 & 30,0 & 14,10 \\
\hline 10 & 531 & 1,55 & 1582,50 & 3798 & 3702 & 00 & 24 & 27 & 1,3 & 25,0 & 13,79 \\
\hline
\end{tabular}

energia na moagem (20,03kWh t-1 ${ }^{-1}$, e maior tempo de moagem, entre todos os moinhos avaliados, uma vez que o moinho 1 apresentou um menor número de martelos (15), porém uma maior área de peneira $\left(1620,00 \mathrm{~cm}^{2}\right)$.

Quanto às estimativas dos valores de DGM (Tabela 2), observa-se que a equação composta pelas variáveis TX, PM, DP e ATP apresentou o maior coeficiente de determinação $(0,85)$, seguido pela equação que considerou as variáveis TX, PM e DP que apresentou um coeficiente de determinação de 0,80 , sendo que ambas apresentaram um efeito significativo $(\mathrm{P}<0,01)$. A equação composta pelas variáveis TX e PM apresentou um baixo coeficiente de determinação $(0,39)$, no entanto, a análise de variância para a eliminação da variável DP apresentou um efeito significativo $(\mathrm{P}<0,05)$.

Estes resultados estão de acordo com os relatos de ZANOTTO et al. (1996) em que o diâmetro dos furos das peneiras, como parâmetro único, tornase insuficiente para indicar, com precisão, a granulometria dos produtos moídos. No mesmo sentido, MARTIN (1988) relatou que as variações, entre as características dos moinhos, influenciam a granulometria do milho processado em moinho de martelos, devendo ser considerados o diâmetro dos furos da peneira, a área de abertura da peneira, a potência do motor, o número de martelos, distância entre os martelos e a peneira, a vazão de moagem, o teor de umidade do grão e o desgaste do moinho.

A TX e o DP apresentaram uma correlação positiva e o PM e ATP uma correlação negativa, podendo-se inferir que, quanto maior o DP maior o DGM (Tabela 2), o que é obtido em vários experimentos onde se utilizaram peneiras, com diferentes diâmetros dos furos, para obtenção de diferentes DGM das partículas do milho (ZANOTTO et al., 1995; ZANOTTO et al., 1996; MONTICELLI et al., 1996a e MONTICELLI et al., 1996b). A correlação positiva, obtida para TX, pode ser atribuído a vários fatores dentre eles o próprio DP, pois é notório a obtenção de um menor tempo de moagem ao se utilizar peneiras com maiores DP, no entanto a TX pode ser resultado de vários fatores atuando conjuntamente. No caso da ATP, deve também ter o conhecimento da área de abertura da peneira (área vazada) para maiores conclusões.

Conclui-se que a variação da taxa de moagem e consumo de energia elétrica pode ser devido às diferenças entre as características dos moinhos, do desgaste devido ao uso e da potência dos motores que equipam os moinhos. A taxa de moagem e o diâmetro dos furos das peneiras apresentaram uma correlação positiva com o diâmetro geométrico médio, e a potência do motor e a área total da peneira uma correlação negativa.

Tabela 2 - Estimativas do diâmetro geométrico médio (DGM) em função da taxa de moagem (TX), potência do motor (PM), diâmetro dos furos da peneira (DP) e área total da peneira (ATP).

\begin{tabular}{lccccc}
\hline Constante & TX & PM & DP & ATP & $\mathrm{R}^{2}$ \\
\hline $330,59^{\mathrm{a}}$ & 494,284 & $-11,844$ & 113,746 & $-0,186$ & 0,85 \\
$175,817^{\text {a }}$ & 456,831 & $-17,862$ & 134,301 & & 0,80 \\
$520,644^{\text {b }}$ & 427,832 & $-16,520$ & & 0,39 \\
$627,626^{\text {c }}$ & 44,134 & & 0,28 \\
\hline \multicolumn{5}{c}{ a - Significativo em nível de 1\% de probabilidade (P<0,01) } \\
b - Significativo em nível de 5\% de probabilidade (P<0,05) \\
c - Não significativo (P>0,05)
\end{tabular}

Ciência Rural, v.35, n.1, jan-fev, 2005. 


\section{REFERÊNCIAS BIBLIOGRÁFICAS}

BIAGI, J.D. Implicações da granulometria de ingredientes na qualidade d e pelets e na economia da produção de rações (Revisão). In: SIMPÓSIO SOBRE GRANULOMETRIA DE INGREDIE NTES E RAÇÕES PARA SUÍNOS E AVES, 1998, Concórdia, SC. Anais... Concórdia, SC : EMBRAPA/CNPSA, 1998. 74p. p.57.

HANDERSON, S.M.; PERRY, R.L. Agricultural process engineering. New York : John Wiley and Sons, 1955. 402p.

HEALY, B.J. et al. Optimum particle size of corn and hard and soft sorghum for nursery pigs. J Anim Sci, v.72, p.2227-2236, 1994.

MARTIN, S. Particle size reduction. NFIA - feed manufacturing short course. Kansas: Kansas State University, 1988. 10p.

MONTICELLI, C.J. et al. Efeito da granulometria do milho, da área por animal e do sexo sobre o desempenho de suínos em crescimento e terminação. R Soc Bras Zootec, v.25, n.6, p.1150-1162, 1996a.
MONTICELLI, C.J. et al. Efeito da granulometria do milho e da área por animal sobre lesões gástricas de suínos nas fases de crescimento e terminação. R Soc Bras Zootec, v.25, n.6, p.1163-1177, 1996b.

OLIVEIRA, P.A.V. et al. Avaliação de sistemas de armazenagem e equipamentos para a produção de rações em pequenas propriedades. In: CONGRESSO BRASILEIRO DE ENGENHARIA AGRÍCOLA, 1991, Londrina, PR. Anais... Londrina, PR : Sociedade Brasileira de Engenharia Agrícola, 1991. V.2, p.1589-1602.

UNIVERSIDADE FEDERAL DE VIÇOSA (UFV). Manual de utilização do programa SAEG (Sistema para análises estatísticas e genéticas). Viçosa, 1999. 59p.

ZANOTTO, D.L. et al. Granulometria do milho na digestibilidade das dietas para suínos em crescimento e terminação. R Soc Bras Zootec, v.24, n.3, p.428-436, 1995.

ZANOTTO, D.L. et al. Desempenho produtivo de suínos submetidos à dietas com diferentes granulometrias do milho. R Soc Bras Zootec, v.25, n.3, p.501-510, 1996. 